\title{
p53 aberrations in low grade endometrioid carcinoma of the endometrium with nodal metastases: possible insights on pathogenesis discerned from immunohistochemistry
}

Oluwole Fadare ${ }^{1 *}$ and Vinita Parkash ${ }^{2}$

\begin{abstract}
Background: TP53 mutations are rarely identified in low grade endometrioid carcinoma of the endometrium, and their pathogenic significance in such tumors is evidenced by the fact that TP53 aberrations have been associated with reduced recurrence-free survival in this subset of tumors. However, TP53 aberrations may not always represent a driving molecular event in a given endometrial cancer with a mutation. In this case study, the immunophenotype of a distinctive low grade endometrioid adenocarcinoma with an unusual pattern of lymph node metastases is used to explore the possible roles for underlying TP53-related molecular events in its pathogenesis.

Case presentation: A low grade endometrioid carcinoma, $9 \mathrm{~cm}$ in greatest dimension, with 35\% invasion of the myometrial wall thickness, focal lymphovascular invasion, and metastases to 2 of 16 pelvic lymph nodes, was diagnosed in a 52-year-old woman. The endometrial tumor showed a p53-mutation (aberrant)-type immunohistochemical pattern in $40 \%$ of the tumor, but the rest of the tumor, as well as the foci of myometrial and lymphovascular invasion, were p53-wild type. Both lymph nodes with metastatic disease showed a distinct biphasic pattern, comprised of both p53-wild type and p53-aberrant areas in tumoral foci that were spatially apposed but not intermixed. Most p53-aberrant areas (at both the lymph nodes and the endometrium) showed a higher mitotic index and increased atypia as compared to the p53-wild type areas; both showed squamous differentiation. The p53-aberrant areas at both locations were also p16-diffusely positive, vimentin-positive, and estrogen/progesterone receptor-positive, whereas the p53-wild type areas showed an identical immunophenotype with the exception of being p16-mosaic positive. All components of the tumor at both the primary and metastatic sites showed loss of MSH2 and MSH6 and retained MLH/PMS2 expression.

(Continued on next page)
\end{abstract}

\footnotetext{
* Correspondence: oluwolefadare@yahoo.com

'Department of Pathology, University of California San Diego Health, 9300

Campus Point Drive, Suite 1-200, MC 7723, La Jolla, CA 92037, USA

Full list of author information is available at the end of the article
} 
(Continued from previous page)

Conclusions: The presence of p53-mutant and wild-type areas in multiple lymph nodes, coupled with the absence of a p53-aberrant immunophenotype in the myometrium-invasive or lymphovascular-invasive portions of the tumor, argues against the possibility that the TP53 mutation in this tumor is a driving event in its pathogenesis, at least regarding the metastatic process. This case illustrates how routine immunohistochemistry can provide important insights into underlying molecular events in cancers, exemplifies an uncommon co-existence of DNA mismatch repair protein deficiency and p53-aberrant immunophenotype in low-grade endometrioid carcinoma, illustrates morphologic differences between p53-aberrant and p53-wild type areas within in the same tumor, and is an exemplar of the emerging theory that lymph node metastases of endometrial cancer may be comprised of different subclones of the primary tumor.

Keywords: Endometrioid carcinoma, Uterus, p53-aberrant, Driver, p53-wild-type,

\section{Background}

The TP53 gene, which is located on 17p13.1 [1], encodes the p53 protein and is one of the most frequently mutated genes in human cancers [2,3]. p53 occupies a central position in a vast, likely integrated but incompletely understood network of cellular signaling that essentially maintains the "genomic health" [3, 4]. Accordingly, inactivation of p53 may result in a cellular environment that is conducive to or permissive of oncogenesis $[3,4]$. Inactivation of p53 may occur through a variety of mechanisms, including mutation of the p53 gene, binding to viral proteins, expansion of its negative regulators, or other alterations of genes and proteins that are directly or indirectly involved in p53-mediated signaling $[4,5]$. The p53 content of cells is generally kept at low levels through an ubiquitin-effectuated proteolytic process that is primarily mediated by the protein MDM2, itself a p53 target, thereby creating a negative feedback loop [4-6]. Mutant forms of p53, in contrast, are stable and accumulate to high levels intracellularly. This has traditionally been attributed to the inability of the p53 mutant protein to optimally transactivate its negative regulator (MDM2), but a comprehensive picture of all contributing factors to the process remain unclear [4-6]. p53 function is inactivated in most human cancers through missense or nonsense/frameshift mutations of the gene [7], which respectively correspond to the protein "overexpression" and "null" patterns of aberrant (i.e. non wild type) p53 immunoreactivity [8].

Among the histotypes of endometrial carcinoma, p53 aberrations represent the most frequently identified recurring molecular event in serous carcinomas $[9,10]$ and carcinosarcomas $[11,12]$ but have also been identified in significant subsets of high grade endometrioid [13], clear cell [14] and dedifferentiated/undifferentiated carcinomas $[15,16]$. Numerous reports have found p53 aberrations to be a significantly negative prognostic factor in endometrial carcinomas in general, although how independent this significance is of the necessarily dependent variables of tumor histotype and tumor grade has been a subject of some debate [17-22]. p53 aberrations are very rarely identified in low grade endometrioid carcinomas and are occasionally identified in intermediate-grade carcinomas. In the TCGA (The Cancer Genome Atlas) dataset, 0 and $11.8 \%$ of grades 1 and 2 endometrioid carcinomas had a TP53 mutation [9]. Recently, Kurnit et al. examined 125 cases of grades 1 and 2, stage 1 and II endometrioid carcinomas by next generation sequencing, and found TP53 mutations, which were present in 9\% of cases, to be associated with worse recurrence-free survival on multivariate analysis [22]. This suggests that the "acquisition" of a TP53 mutation in a low-stage, low-grade endometrioid carcinoma is of adverse prognostic significance and is accordingly a significant event in its pathogenesis.

Only 7\% of endometrial carcinomas show a DNA mismatch repair protein (MMR) deficiency that is unrelated to MLH1 promoter hypermethylation [23], and as was previously indicated, TP53 mutations are uncommon in low grade endometrioid carcinoma [9]. The combination, i.e. TP53 mutations in a low grade endometrioid carcinoma with MMR deficiency unrelated to promoter hypermethylation, is distinctly uncommon. In this report, the authors describe one such case - a low grade endometrioid carcinoma of the endometrium showing a p53-aberrant immunophenotype in one portion of the tumor, MSH2 and MSH6 loss in all components, and a distinctive pattern of lymph node metastases in multiple lymph nodes comprised of both the p53 wild-type and p53-aberrant components. The unique aspects of this case are used to explore the role of TP53 mutation in the case, its implications on the subclone theory of tumor metastases, and how immunohistochemistry may potentially provide valuable insights into these events

\section{Case presentation}

A 52-year-old woman, gravida-3, para-3, 3 years postmenopausal, presented with post-menopausal bleeding of "several weeks" duration. She ultimately underwent a biopsy on which a diagnosis of endometrioid adenocarcinoma, FIGO grade 1 was rendered. Imaging showed a left adnexal mass whose features were equivocal regarding 
benignancy. A decision was made to perform a total hysterectomy and bilateral salpingo-oophorectomy. An intraoperative pathologic assessment was performed, which showed the adnexal mass to be benign but the endometrial mass to be of large volume $($ a $9 \times 6 \mathrm{~cm}$ soft polypoid mass that occupied the entirety of the uterine cavity) with myometrial invasion and lower uterine segment involvement. A bilateral pelvic lymphadenectomy was also performed. Microscopic examination of the permanent sections of the case showed a grade 1 endometrioid carcinoma of the endometrium, with $35 \%$ invasion of the myometrial wall thickness, focal lymphovascular invasion, and metastases to 2 of 16 pelvic lymph nodes (Figs. 1 and 2). Approximately $40 \%$ of the tumor was comprised of columnar glands showing more nuclear stratification, more nuclear enlargement, and more prominent nucleolomegaly than the background glands (atypical areas). These areas also showed comparatively increased mitotic indices (average $17 \mathrm{MF} / 10 \mathrm{HPF}$ ) than the background glands (average $9 \mathrm{MF} / 10 \mathrm{HPF}$ ), from which they were spatially distinct. Immunohistochemically, the atypical areas showed a p53 aberrant immunophenotype, characterized by diffuse and marked nuclear positivity for p53 in more than $90 \%$ of lesional nuclei. The p53-aberrant areas were also p16-diffusely positive, vimentin-positive, Napsin Anegative, estrogen receptor positive, and progesterone receptor-positive (Fig. 1). The remainder of the tumor (60\% of tumoral volume) displayed a p53-wild type immunophenotype, and were p16-mosaic positive, vimentinpositive, Napsin A-negative, estrogen receptor positive, and progesterone receptor-positive. As such, the p53aberrant and p53-wild type areas showed an identical immunophenotype with the exception of the latter being p16-mosaic positive. Foci of lymphovascular invasion and myometrial invasion showed a p53-wild type immunophenotype and were identical in immunophenotype to the other p53-wild type areas within the tumor. Areas of background hyperplasia showed a p53 wild type immunophenotype. The endometrioid carcinoma at its primary site showed minor squamous differentiation, and no solid components in both the p53-wild type and p53-aberrant areas.

The 2 lymph nodes with metastatic disease each showed a distinct biphasic pattern, comprised of both p53-wild

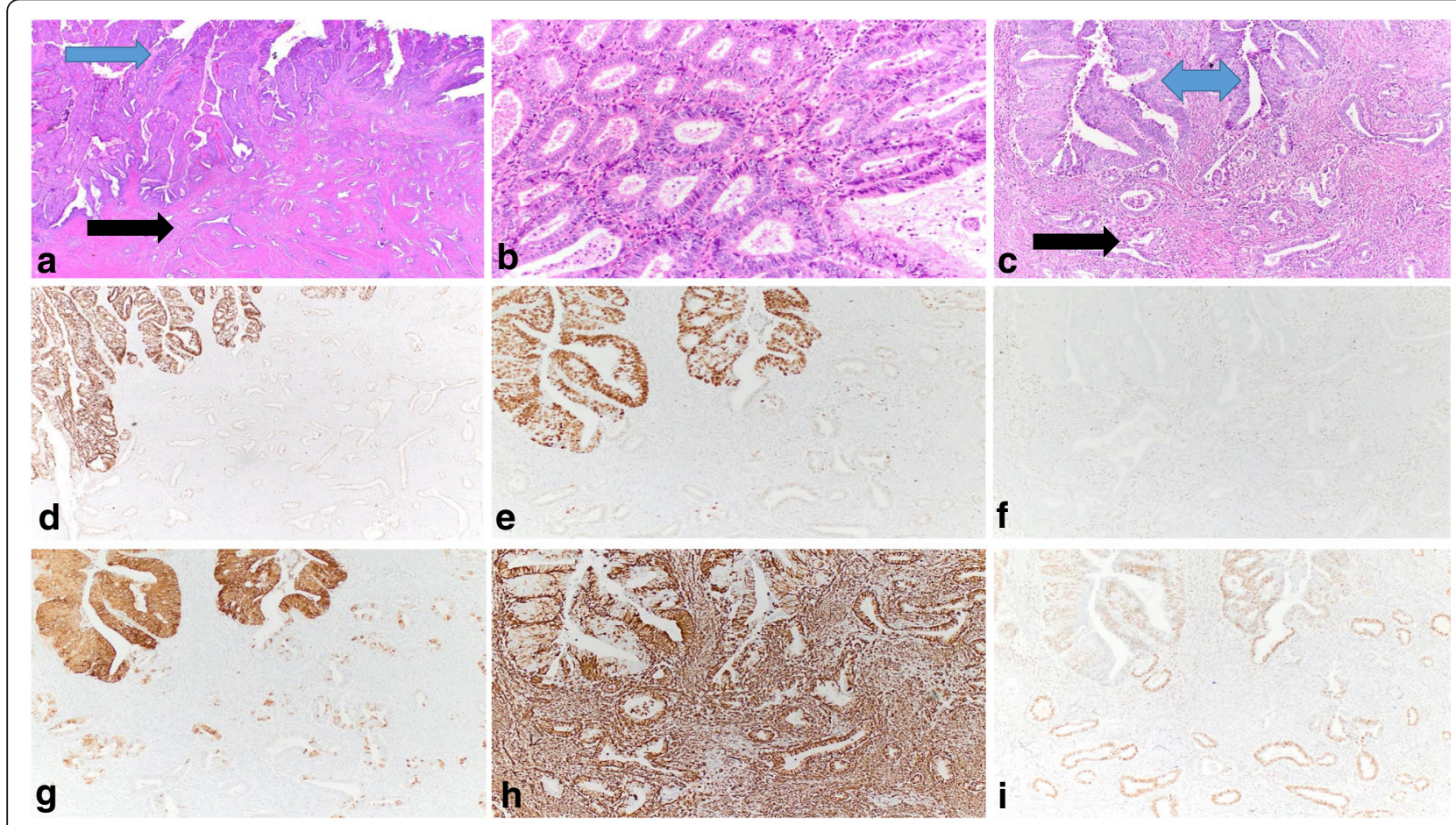

Fig. 1 Morphologic and immunophenotypic features of tumor in the uterus: a Focus of myometrial invasion (black arrow) with overlying endometrial tumor (blue arrow) ( $\mathrm{H}$ and $\mathrm{E}$, original magnification: $2 \mathrm{x}$ ). $\mathbf{b}$ The p53-wild type areas of the tumor ( $\mathrm{H}$ and $\mathrm{E}$, original magnification: 40X). $\mathbf{c}$ Transitional areas between myoinvasive glands (black arrow) and overlying, non-myoinvasive parts of tumor (blue arrow) ( $\mathrm{H}$ and $\mathrm{E}$, original magnification: 40X). $\mathbf{d}$ and e p53 immunohistochemistry showing wild-type staining pattern in the myoinvasive glands and aberrant staining pattern in the overlying, nonmyoinvasive parts of tumor (original magnifications: 1D: 2X; 1E: 10X). $\mathbf{f}$ Loss of MSH2 in both components of the tumor (original magnification: 10X). $\mathbf{g}$ p16 immunohistochemistry showing mosaic staining pattern in the myoinvasive glands and diffuse staining pattern in the overlying, non-myoinvasive parts of tumor (original magnification: 10X). $\mathbf{h}$ Vimentin expression in both components of the tumor (original magnification: 10X). $\mathbf{i}$ Estrogen receptor expression in both components of the tumor (original magnification: 10x) 


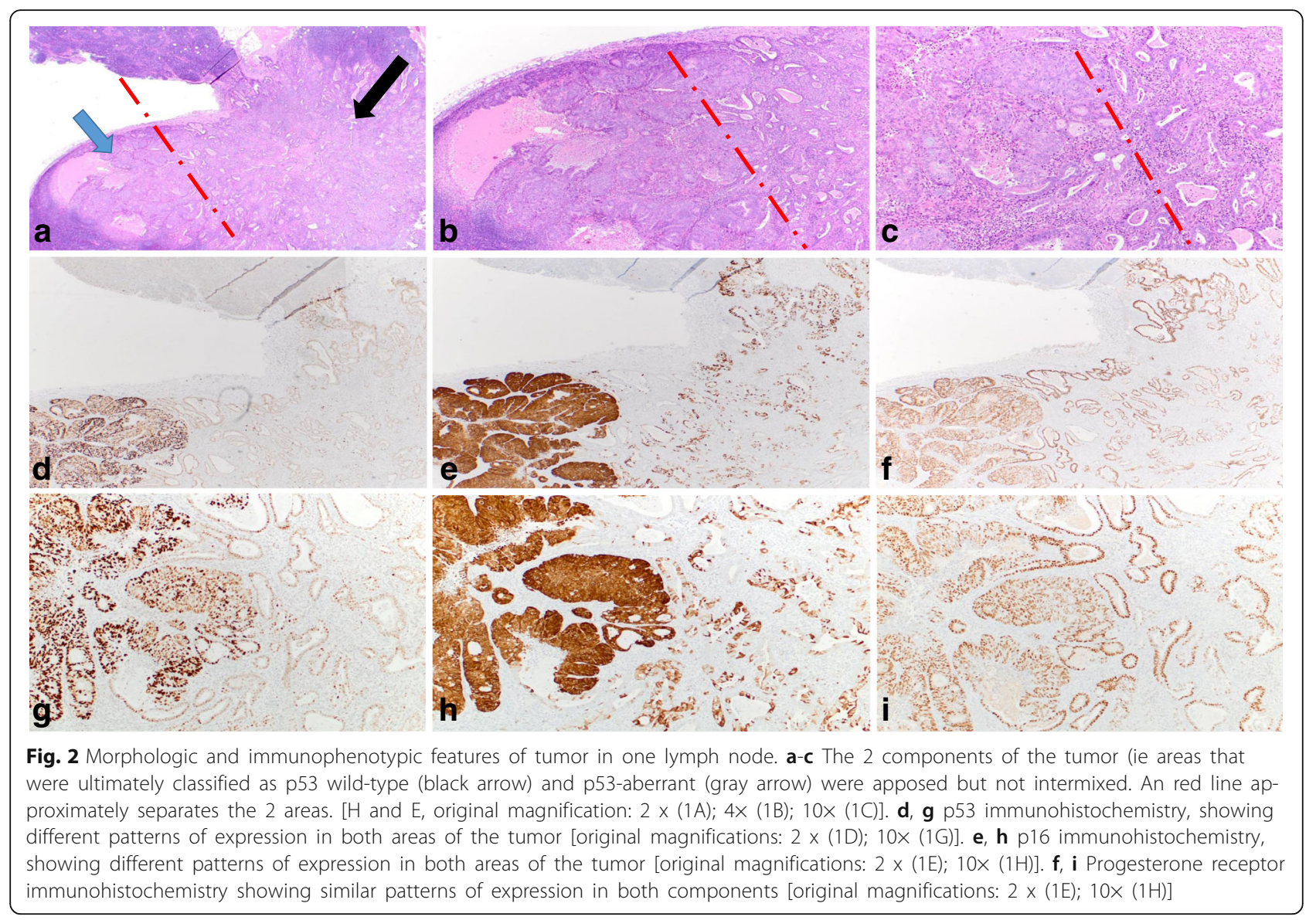

type and p53-aberrant areas in foci that were spatially apposed but not intermixed. The p53-aberrant areas were identical in morphology and immunophenotype to the "atypical areas" of the endometrial tumor described above. The p53-wild type tumoral areas were comprised of glands with less columnar configuration and more nonspecific cytoplasmic clarity. However, they showed foci of squamous differentiation and were otherwise immunophenotypically identical to the p53-wild type areas within the endometrial tumor (Fig. 2). All components of the tumor at both the primary and metastatic sites showed loss of MSH2 and MSH6 with retained expression of MLH1 and PMS2. The patient declined germ-line testing, and underwent adjuvant chemotherapy. The case is too recent for meaningful follow-up.

All immunohistochemical studies were performed on $4 \mu$-thick, unstained slides of formalin-fixed, paraffinembedded tissue sections using the Ventana Benchmark automation and the Ultra View detection kit (Ventana Medical Systems, Tucson, AZ) and the following primary antibodies: Estrogen receptor (ER; Clone SP1; prediluted, Ventana), Progesterone receptor (PR; clone IE2; prediluted; Ventana), p53 (clone DO-7; dilution 1:40; Ventana), Napsin-A (polyclonal, prediluted; Cell
Marque, Rocklin, CA), Vimentin (clone V9, dilution 1: 1000, Ventana), p16 (Clone JC8, prediluted, Santa-Cruz, Dallas, TX), MLH1 (clone G168-15, prediluted, Biocare Medical, Concord, CA), PMS2 (Clone A16-4; dilution 1:25; BD Biosciences, San Jose, CA), MSH2 (clone FE11, prediluted, Biocare Medical), and MSH6 (clone $\mathrm{BC} / 44$, prediluted, Biocare Medical).

\section{Discussion}

Approximately $8 \%$ of the 65 hypermutated (microsatellite unstable) endometrial carcinomas in the TCGA data set showed a TP53 mutation [9]. The grade distribution for those TP53-mutant, hypermutated cases were not outlined [9]. However, in one comparable analysis of 319 cases that sought to recreate the molecular subgroups of the TCGA study, only 8 (2.5\%) of 319 cases concurrently displayed a TP53 mutation and a DNA MMR protein deficiency, and all 8 cases were high grade carcinomas [24]. A case of a low-grade endometrioid carcinoma of the endometrium showing a p53-aberrant immunophenotype in one portion of the tumor, MSH2 and MSH6 loss in all components, and a distinctive pattern of lymph node metastases, is described herein. It is the 
authors' experience that this combination is extraordinary uncommon.

DNA mismatch repair proteins recognize and correct errors that may arise during DNA replication and recombination, and inactivation of DNA mismatch repair can increase spontaneous mutation rates, which in turn increases the likelihood of oncogenesis [25]. Similarly, among a myriad of other cellular functions, TP53 is a tumor suppressor gene that prevents the propagation of potentially oncogenic events by inducing apoptosis [1-7]. Therefore, a loss of function in both systems may theoretically have a synergistic effect. Indeed, in vitro analyses of colon cancer cell lines has shown that loss of function of both systems synergistically increases the frequency of mutations, promotes genomic instability under stress, and increases chemoresistance [26-28]. Other in vitro evidence suggest the existence of some interaction between the 2 systems, but a clear picture is lacking [29-32].

Somatic mutations in cancer genomes have traditionally been categorized into 2 major groups based on the consequences of those mutations on oncogenesis and/or cancer evolution: "Driver" mutations result in a selective growth advantage to cells that harbor them [33, 34]. Cells with driver mutations were selected for at some point in the evolution of the cancer, and are often implicated in the causality and maintenance of the cancer [33]. As such, they are identified at a relatively high frequency in a cancer of a particular type [35]. "Passenger" mutations, which greatly outnumber driver mutations, have traditionally been thought to not confer a growth advantage and to have a limited role in oncogenesis [33]. Recently, an additional "mini-driver" model has been proposed, in which some somatic mutations are neither passengers nor drivers, but are "mini-drivers", each with "relatively weak tumor-promoting effects", but which may cumulatively display major tumordriving tumorigenic effects under the right conditions [36]. Other recent proposals include the "latent driver" model in which some mutations generally behave as passengers but can drive cancer development when coupled with other mutations [37], and a model in which passenger mutations are not simply neutral events, but which may have cumulative effects that actually slow or prevent tumor progression [38, 39].

The morphologic and immunophenotypic findings in the current tumor are of interest in deciphering whether the p53 mutation that was apparently acquired in one portion of the tumor was a driving or passenger event in lymph node metastases. As was previously noted, TP53 mutations in low and intermediate grade endometrioid carcinomas have been associated with reduced survival [22], and studies of endometrial cancer cell lines have showed that TP53 mutation increases invasion and migration, and therefore likely promote metastases [40].
However, in the current case, it is unlikely that TP53 mutation was the primary driving event. Most $-60 \%$ - of the tumor was p53-wild type, including foci of background hyperplasia, which suggests that the p53aberrant areas were a manifestation of a subclone of p53-mutated tumor within this background. The areas of the tumor that displayed "aggressive" features (i.e. myometrial invasion and lymphovascular invasion) all showed a p53-wild-type immunophenotype, which argues against the possibility that the p53-aberrant clone was particularly aggressive. More importantly, the findings in the lymph nodes argue against the possibility. If there had been a clonal expansion of an aggressive TP53-mutant clone in the endometrial cancer, the lymph node metastases would be expected to be p53-aberrant in their entirety. In contrast, the presence of multiple lymph nodes with p53-wild type tumor concurrent with their p53-mutant counterparts suggests that the TP53 aberration in this case may function no more than as a mini-driver, possibly synergizing with other molecular events, but not being the primary driving force in the metastatic process.

This case may also have some implications regarding the larger "subclone" theory of metastases [41]. This theory proffers that a given cancer is composed of subpopulations (subclones) of cells that are heterogeneous regarding a variety of molecular properties, including the potential for metastasis, and that subclones with metastatic potential can emerge at various points in the lifecycle of a tumor [41]. One recent study of colorectal cancer in which high-confidence phylogenetic trees were constructed using hypermutable DNA found that in 65\% of cases, metastases arose from independent subclones of the primary tumor [42]. An earlier study, also on colorectal cancer, had reported that individual node metastasis are comprised of multiple sub-clones from the primary tumor [43]. In the current case, the primary tumors and their metastases indeed showed an identical overall immunophenotype. However, the two tumor-positive lymph nodes each seemed to harbor 2 clones of the same tumor, with each node showing p53-wild type areas and p53-aberrant areas in different areas of a contiguous nodal deposit. One potential explanation is that the TP53 mutation in the lymph node metastases was newly acquired there, and is unrelated to the TP53 mutation in the endometrial tumor. In support of this possibility is the finding that about one-half of mutations that are present in endometrial cancer metastases are absent in their matched primary tumors [44]. Arguing against this possibility is the fact that in the present case, metastases in two different lymph nodes showed this "biclonal" morphology, since it is highly unlikely that metastatic deposits in 2 separate lymph nodes each 
acquired an unrelated TP53 mutation. Overall, the subclone theory appears to be more probable.

Irrespective of how the nodal tumors acquired a TP53 mutation, the pattern of metastases arguably bolsters the point that the TP53 mutation in this case was not the driving event, at least with regard to the promotion of lymph node metastases. As was previously noted, a clonal expansion of an aggressive TP53-mutant clone in the endometrial cancer should result in lymph node metastases that are p53-aberrant in their entirety. In contrast, TP53-aberration as a passenger mutation may theoretically be unrelated to the metastatic process in the case. The critical molecular event driving metastases appeared to be, at minimum, incompletely dependent on TP53. It is unclear whether the driving event in this case is loss of MSH2/MSH6. In one recent study from the ProMisE (Proactive Molecular Risk Classifier for Endometrial Cancer) group, patients in the MMR-deficient subgroup (defined as those displaying loss of PMS2 and MSH6) had relatively poor outcomes [24], although in general, the prognostic significance of DNA MMR protein deficiency in endometrial cancer is still the subject of debate $[45,46]$.

It is perhaps expected that tumors with a high mutational burden, including ultramutated cancers (typically those harboring a POLE exonuclease domain mutation) and hypermutated cancers (typically those that are microsatellite unstable) would also harbor the most commonly altered cancer gene, TP53, with a significant frequency. The POLE mutation status of the present case is unknown. Nonetheless, the ongoing challenge in cancers in general is to identify the most significant alterations. With the increasing availability of genomic information in cancers, distinguishing between passenger mutations with limited clinical consequence, and driver mutations that would likely affect outcome takes on added importance. We hypothesize that in endometrial endometrioid carcinomas, the role of TP53, much like the gene itself, is variable, driving pathogenesis in some instances, being a passenger in others, and serving in others in a myriad of "intermediate" roles in another subset.

The proportion of low grade endometrioid carcinomas that display a TP53 mutation is very low [9, $22]$, and it is even more uncommon in our experience for a low grade endometrioid carcinoma to show a p53-aberrant immunophenotype in only one portion of the tumor. This offered a rare opportunity to study within the same case the morphologic and immunophenotypic differences between the p53-aberrant and p53-wild type areas. At both their primary and metastatic sites, we found that the p53-aberrant areas were more mitotically active than the p53 wild-type areas and showed more atypia, as evidence by more nuclear stratification, more nuclear enlargement, and more prominent nucleolomegaly (Fig. 3). However, we did not think that the changes were sufficiently distinctive to allow the confident delineation of cancers that are likely to be p53-aberrant by their morphologic features alone.

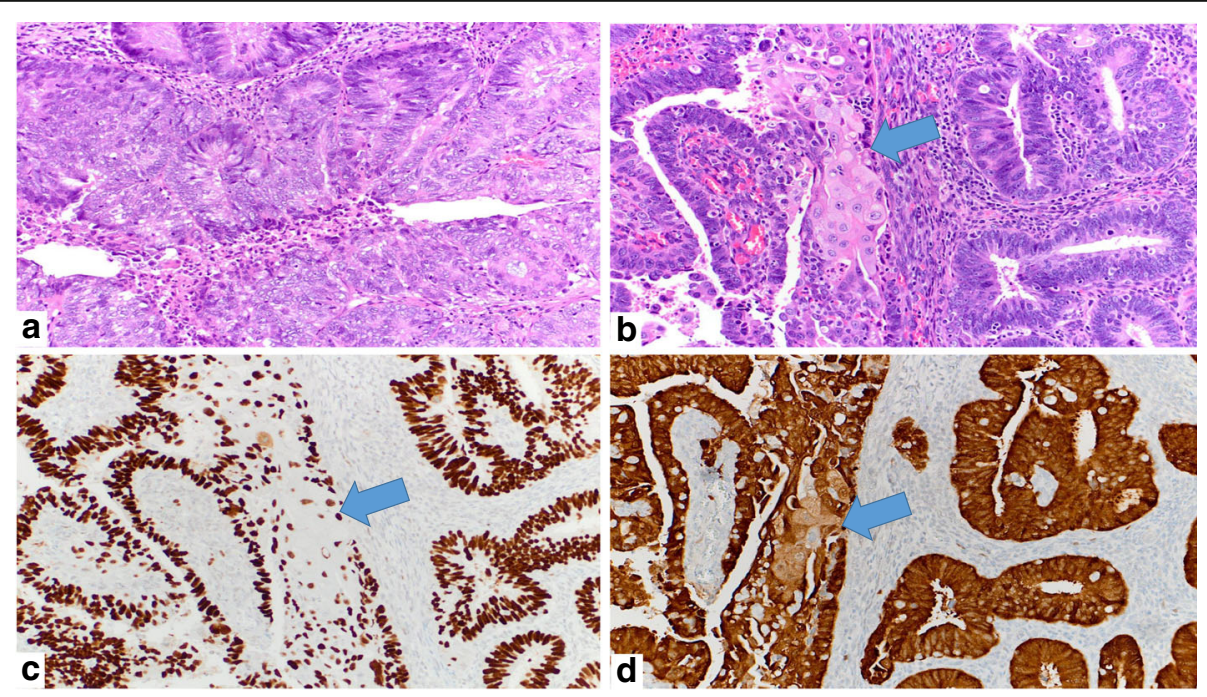

Fig. 3 Morphologic and immunophenotypic features of the p53-aberrant areas of tumor at its primary site (arrows indicate focus of squamous differentiation, consistent with an endometrioid histotype). a, b Morphologic features, showing increased atypia and mitotic activity in a p53aberrant area of the tumor, compared to the p53-wild type areas as illustrated in Fig. 1b [H and E, original magnification: 40 x]. c p53-aberrant immunophenotype. [original magnifications: $\times 40$ ]. $\mathbf{d}, 1 \mathrm{H}$ : p16-diffusely positive immunophenotype. [original magnifications: $\times 40$ ] 


\section{Conclusions}

This case illustrates how routine immunohistochemistry can provide important insights into underlying molecular events in cancers, exemplifies an uncommon co-existence of a DNA mismatch repair protein deficiency and a p53-aberrant immunophenotype in low-grade endometrioid carcinoma, illustrates morphologic differences between p53-aberrant and p53wild type areas in the same tumor, and is exemplary of the emerging theory that lymph node metastases may be comprised of different subclones of the primary tumor.

\section{Abbreviations \\ DNA: Deoxyribonucleic acid; HPF: high power fields; MDM2: Mouse double minute 2 homolog; MF: mitotic figures; MLH1: MutL homolog 1; MSH2: MutS protein homolog 2; MSH6: MutS protein homolog 6; PMS2: PMS1 Homolog 2; POLE: DNA Polymerase Epsilon; TCGA: The Cancer Genome Atlas; TP53: Tumor protein p53}

\section{Acknowledgements}

Not applicable.

\section{Funding}

No funding was received for this case report.

\section{Availability of data and materials}

Not applicable.

\section{Authors' contributions}

OF: primary diagnostic assessment. VP, OF: conception, writing and revision of manuscript. Both authors read and approved the final manuscript.

\section{Ethics approval and consent to participate}

Not applicable.

\section{Consent for publication}

Written informed consent was obtained from the patient for publication of this case report and any accompanying images. A copy of the written consent is available for review by the Editor-in-Chief of this journal.

\section{Competing interests}

The authors declare that they have no competing interests.

\section{Publisher's Note}

Springer Nature remains neutral with regard to jurisdictional claims in published maps and institutional affiliations.

\section{Author details}

'Department of Pathology, University of California San Diego Health, 9300 Campus Point Drive, Suite 1-200, MC 7723, La Jolla, CA 92037, USA

2Department of Pathology, Yale School of Medicine, New Haven, CT, USA.

Received: 2 August 2017 Accepted: 7 November 2017

Published online: 14 November 2017

\section{References}

1. Baker SJ, Fearon ER, Nigro JM, Hamilton SR, Preisinger AC, Jessup JM, vanTuinen $\mathrm{P}$, Ledbetter DH, Barker DF, Nakamura Y, White R, Vogelstein B. Chromosome 17 deletions and p53 gene mutations in colorectal carcinomas. Science. 1989;244(4901):217-21.

2. Olivier M, Hollstein M, Hainaut P. TP53 mutations in human cancers: origins, consequences, and clinical use. Cold Spring Harb Perspect Biol. 2010:2(1):a001008

3. Nigro JM, Baker SJ, Preisinger AC, Jessup JM, Hostetter R, Cleary K, Bigner SH, Davidson N, Baylin S, Devilee P, et al. Mutations in the p53 gene occur in diverse human tumour types. Nature. 1989;342(6250):705-8.
4. Vogelstein B, Lane D, Levine AJ. Surfing the p53 network. Nature. 2000; 408(6810):307-10.

5. Freed-Pastor WA, Prives C. Mutant p53: one name, many proteins. Genes Dev. 2012;26:1268-86.

6. Oren M, Rotter V. Mutant p53 gain-of-function in cancer. Cold Spring Harb Perspect Biol. 2010;2(2):a001107.

7. Bouaoun L, Sonkin D, Ardin M, Hollstein M, Byrnes G, Zavadil J, Olivier M. TP53 Variations in Human Cancers: New Lessons from the IARC TP53 Database and Genomics Data. Hum Mutat. 2016;37:865-76.

8. McCluggage WG, Soslow RA, Gilks CB. Patterns of p53 immunoreactivity in endometrial carcinomas: 'all or nothing' staining is of importance. Histopathology. 2011;59:786-8.

9. Cancer Genome Atlas Research Network, Kandoth C, Schultz N, Cherniack AD, Akbani R, Liu Y, Shen H, Robertson AG, Pashtan I, Shen R, Benz CC, Yau C, Laird PW, ding L, Zhang W, Mills GB, Kucherlapati R, Mardis ER, Levine DA. Integrated genomic characterization of endometrial carcinoma. Nature. 2013;497(7447):67-73.

10. Fadare $\mathrm{O}$, Zheng $\mathrm{W}$. Insights into endometrial serous carcinogenesis and progression. Int J Clin Exp Pathol. 2009;2:411-32

11. Lopez-Garcia MA, Palacios J. Pathologic and molecular features of uterine carcinosarcomas. Semin Diagn Pathol. 2010;27:274-86.

12. Cherniack AD, Shen $H$, Walter $V$, Stewart C, Murray BA, Bowlby R, Hu X, Ling S, Soslow RA, Broaddus RR, Zuna RE, Robertson G, Laird PW, Kucherlapati R, Mills GB; cancer genome atlas research network, Weinstein JN, Zhang J, Akbani R, Levine DA Integrated Molecular Characterization of Uterine Carcinosarcoma Cancer Cell 2017:31:411-423.

13. Alvarez T, Miller E, Duska L, Oliva E. Molecular profile of grade 3 endometrioid endometrial carcinoma: is it a type I or type II endometrial carcinoma? Am J Surg Pathol. 2012;36:753-61.

14. Fadare O, Gwin K, Desouki MM, Crispens MA, Jones HW 3rd, Khabele D, Liang SX, Zheng W, Mohammed K, Hecht JL, Parkash V. The clinicopathologic significance of p53 and BAF-250a (ARID1A) expression in clear cell carcinoma of the endometrium. Mod Pathol 2013:26:1101-1110.

15. Ramalingam P, Masand RP, Euscher ED, Malpica A. Undifferentiated carcinoma of the endometrium: an expanded Immunohistochemical analysis including PAX-8 and basal-like carcinoma surrogate markers. Int J Gynecol Pathol. 2016:35:410-8.

16. Hoang LN, Lee YS, Karnezis AN, Tessier-Cloutier B, Almandani N, Coatham M, Gilks CB, Soslow RA, Stewart CJ, Köbel M, Lee CH. Immunophenotypic features of dedifferentiated endometrial carcinoma - insights from BRG1/ INI1-deficient tumours. Histopathology. 2016;69:560-9.

17. Garcia-Dios DA, Lambrechts D, Coenegrachts L, Vandenput I, Capoen a, Webb PM, Ferguson K, ANECS, Akslen LA, Claes B, Vergote I, Moerman P, van Robays J, Marcickiewicz J, Salvesen HB, Spurdle AB, Amant F. High-throughput interrogation of PIK3CA, PTEN, KRAS, FBXW7 and TP53 mutations in primary endometrial carcinoma. Gynecol Oncol. 2013;128:327-34.

18. Geisler JP, Geisler HE, Wiemann MC, Zhou Z, Miller GA, Crabtree W. p53 expression as a prognostic indicator of 5-year survival in endometrial cancer. Gynecol Oncol. 1999;74:468-71.

19. Seeger A, Kölbl H, Petry IB, Gebhard S, Battista MJ, Böhm D, Steiner E. p53 is correlated with low BMI negative progesterone receptor status and recurring disease in patients with endometrial cancer. Gynecol Oncol. 2012;125:200-7

20. Lee EJ, Kim TJ, Kim DS, Choi CH, Lee JW, Lee JH, Bae DS, Kim BG, p53 alteration independently predicts poor outcomes in patients with endometrial cancer: a clinicopathologic study of 131 cases and literature review. Gynecol Oncol. 2010;116:533-8.

21. Urabe $R$, Hachisuga $T$, Kurita $T$, Kagami $S$, Kawagoe $T$, Matsuura $Y$, Shimajiri S. Prognostic significance of overexpression of p53 in uterine endometrioid adenocarcinomas with an analysis of nuclear grade. J Obstet Gynaecol Res. 2014:40:812-9.

22. Kurnit KC, Kim GN, Fellman BM, Urbauer DL, Mills GB, Zhang W, Broaddus RR. CTNNB1 (beta-catenin) mutation identifies low grade, early stage endometrial cancer patients at increased risk of recurrence. Mod Pathol. 2017:30:1032-41.

23. Mills AM, Liou S, Ford JM, Berek JS, Pai RK, Longacre TA. Lynch syndrome screening should be considered for all patients with newly diagnosed endometrial cancer. Am J Surg Pathol. 2014;38:1501-9.

24. Talhouk A, McConechy MK, Leung S, Yang W, Lum A, Senz J, Boyd N, Pike J, Anglesio M, Kwon JS, Karnezis AN, Huntsman DG, Gilks CB, McAlpine JN Confirmation of ProMisE: a simple, genomics-based clinical classifier for endometrial cancer. Cancer. 2017;123:802-13. 
25. Kunkel TA, Erie DADNA. Mismatch repair. Annu Rev Biochem. 2005;74:681-710.

26. Lin X, Ramamurthi K, Mishima M, Kondo A, Howell SB. p53 interacts with the DNA mismatch repair system to modulate the cytotoxicity and mutagenicity of hydrogen peroxide. Mol Pharmacol. 2000:58:1222-9.

27. Lin X, Ramamurthi K, Mishima M, Kondo A, Christen RD, Howell SB. P53 modulates the effect of loss of DNA mismatch repair on the sensitivity of human colon cancer cells to the cytotoxic and mutagenic effects of cisplatin. Cancer Res. 2001;61:1508-16.

28. Lin X, Howell SBDNA. Mismatch repair and p53 function are major determinants of the rate of development of cisplatin resistance. Mol Cancer Ther. 2006;5:1239-47.

29. Wu J, Gu L, Wang H, Geacintov NE, Li GM. Mismatch repair processing of carcinogen-DNA adducts triggers apoptosis. Mol Cell Biol. 1999;19:8292-301.

30. Xinarianos G, Liloglou T, Prime W, Sourvinos G, Karachristos A, Gosney JR, Spandidos DA, Field JK. p53 status correlates with the differential expression of the DNA mismatch repair protein MSH2 in non-small cell lung carcinoma. Int J Cancer. 2002;101:248-52.

31. Scherer SJ, Welter C, Zang KD, Dooley S. Specific in vitro binding ofp53 to the promoter region of the human mismatch repair gene hMSH2. Biochem Biophys Res Commun. 1996;221:722-3.

32. Scherer SJ, Maier SM, Seifert M, Hanselmann RG, Zang KD, Muel-lerHermelink HK, Angel P, Welter C, Schartl M. p53 and c-Jun functionally synergize in the regulation of the DNA repair genehMSH2 in response to UV. J Biol Chem. 2000;345:37469-73.

33. Stratton MR, Campbell PJ, Futreal PA. The cancer genome. Nature. 2009; 458(7239):719-24.

34. Marx V. Cancer genomes: discerning drivers from passengers. Nat Methods. 2014 Mar 28;11:375-9.

35. Lawrence MS, Stojanov P, Mermel CH, Robinson JT, Garraway LA, Golub TR, Meyerson M, Gabriel SB, Lander ES, Getz G. Discovery and saturation analysis of cancer genes across 21 tumour types. Nature. 2014;505(7484):495-501.

36. Castro-Giner F, Ratcliffe P, Tomlinson I. The mini-driver model of polygenic cancer evolution. Nat Rev Cancer. 2015;15:680-5.

37. Nussinov R, Tsai CJ. Latent drivers' expand the cancer mutational landscape. Curr Opin Struct Biol. 2015 Jun;32:25-32

38. McFarland CD, Korolev KS, Kryukov GV, Sunyaev SR, Mirny LA. Impact of deleterious passenger mutations on cancer progression. Proc Natl Acad Sci U S A. 2013;110:2910-5.

39. McFarland C, Yaglom JA, Wojtkowiak JW, Scott J, Morse DL, Sherman MY, Mirny $L$. The damaging effect of passenger mutations on cancer progression. Cancer Res. 2017:canres.3283.2015. https://doi.org/10.1158/ 0008-5472.CAN-15-3283-T. Epub ahead of print.

40. Dong P, Tada M, Hamada J, Nakamura A, Moriuchi T, Sakuragi N. p53 dominant-negative mutant $\mathrm{R} 273 \mathrm{H}$ promotes invasion and migration of human endometrial cancer HHUA cells. Clin Exp Metastasis. 2007;24:471-83.

41. Turajlic S, Swanton C. Metastasis as an evolutionary process. Science. 2016; 352(6282):169-75.

42. Naxerova $K$, Reiter JG, Brachtel $E$, Lennerz JK, van de Wetering M, Rowan A, Cai T, Clevers H, Swanton C, Nowak MA, Elledge SJ, Jain RK. Origins of lymphatic and distant metastases in human colorectal cancer. Science. 2017;357(6346):55-60.

43. Hardiman KM, Ulintz PJ, Greenson JK, Wu R, Fearon ER. Complex sub-clonal populations in colorectal cancer lymph node metastasis. [abstract]. In: Proceedings of the AACR Special Conference on Colorectal Cancer: From Initiation to Outcomes; 2016 Sep 17-20; Tampa. Philadelphia (PA): AACR; Cancer Res 2017;77(3 Suppl):Abstract nr PR07.

44. Gibson WJ, Hoivik EA, Halle MK, Taylor-Weiner A, Cherniack AD, Berg A, Holst F, Zack TI, Werner HM, Staby KM, Rosenberg M, Stefansson IM, Kusonmano K, Chevalier A, Mauland KK, Trovik J, Krakstad C, Giannakis M, Hodis E, Woie K, Bjorge L, Vintermyr OK, Wala JA, Lawrence MS, Getz G, Carter SL, Beroukhim R, Salvesen HB. The genomic landscape and evolution of endometrial carcinoma progression and abdominopelvic metastasis. Nat Genet. 2016;48:848-55.

45. Shikama A, Minaguchi T, Matsumoto K, Akiyama-Abe A, Nakamura Y, Michikami H, Nakao S, Sakurai M, Ochi H, Onuki M, Satoh T, Oki A, Yoshikawa H. Clinicopathologic implications of DNA mismatch repair status in endometrial carcinomas. Gynecol Oncol. 2016;140:226-33.

46. Chu MM, Liu SS, Tam KF, Ip PP, Cheung AN, Ngan HY. The significance of mismatch repair deficiency in young patients with endometrial cancer. Int J Gynecol Pathol. 2015;34:403-10.

\section{Submit your next manuscript to BioMed Central and we will help you at every step:}

- We accept pre-submission inquiries

- Our selector tool helps you to find the most relevant journal

- We provide round the clock customer support

- Convenient online submission

- Thorough peer review

- Inclusion in PubMed and all major indexing services

- Maximum visibility for your research

Submit your manuscript at www.biomedcentral.com/submit
Biomed Central 